\title{
Postoperative Analgesia after Cardiac Surgery: Is there a Safe Alternative to Opioids?
}

\author{
Vedat Eljezi
}

Department of Anesthesia and Intensive Care, Division of Cardiac Surgery, University Clinical Center Gabriel Montpied, Clermont Ferrand, France

Submitted: 27.10.2019 Accepted: 19.12.2019

Correspondence: Vedat Eljezi, 58 Rue De Montalembert 63003 Clermont Ferrand - France
Cardiac surgery performed with median sternotomy is an important source of postoperative pain in both intensive care and surgery ward. After cardiac surgery, 30 to $75 \%$ of the patients report moderate to severe acute pain. ${ }^{[l]}$ The most intense pain localization during the first days is the sternotomy site. The most intense pain is that induced by the movements or "dynamic pain," especially those of coughing and deep breathing, and those made to turn in or get out of bed. ${ }^{[2]}$

Postoperative pain causes a complex response, characterized by significant endocrine and metabolic changes that may contribute to complications, such as myocardial ischemia, arrhythmia, hyper-coagulation, pulmonary complications, delirium, or surgical wound infection. ${ }^{[2]}$

Treatment of pain after cardiac surgery is a challenge for the clinician,,$^{[3]}$ especially when patients are elderly and have multiple comorbidities. ${ }^{[4]}$

Opioids are the main agents used to treat acute pain after major surgery, including cardiac surgery. However, the efficacy of analgesia provided by opioids may be tempered by their adverse effects, which may prevent rapid postoperative recovery. In addition to usual side effects, such as postoperative nausea and vomiting (PONV), sedation, confusion, transit delay, urinary retention and pruritus, ${ }^{[5]}$ opioids may impair immunity, ${ }^{[6]}$ may cause hyperalgesia ${ }^{[7]}$ and other less known side effects, such as serotonin syndrome, adrenal insufficiency and decreased circulating levels of sex hormones. All of these adverse effects of opioids are associated with a significant impact on the costs of hospital treatment. ${ }^{[8]}$

The concept of multimodal analgesia introduced more than twenty years ago by $\mathrm{H}$. Kehlet consists of combining different pharmacological agents and techniques that produce analgesic effects at different stages of the nociceptive pathways. The goal is the improvement of analgesia and the reduction of opioid-related adverse effects. To treat pain after cardiac surgery, paracetamol is not very effective, ${ }^{\left[{ }^{[9]}\right.}$ ketamine has psychodysleptic effects, gabapentinoides have a modest effect, and dexmedetomidine has an important sedative effect remains and is expensive. ${ }^{[3]}$

Two particularly interesting analgesic techniques after cardiac surgery are locoregional analgesic techniques and the use of nonsteroidal anti-inflammatory drugs (NSAIDs) because of effective analgesia on dynamic pain. The local anesthetics, in addition to their direct nociception blocking effect through blocking of sodium channels, have other so-called "alternative" effects, such as anti-inflammatory, antioxidant, anti- hyperalgesic, and neuroprotective properties. ${ }^{[0]}$

Epidural analgesia is known to be effective but difficult to practice in a large number of patients after cardiac surgery because of risk of peri-medullary hematoma and other technical problems of insertion and dysfunction. ${ }^{\left[{ }^{11]}\right]}$ This explains why only $7 \%$ of anesthesiologists practice this type of analgesia after cardiac surgery. ${ }^{[12]}$

The use of bilateral sternal (BLS) perfusion of local anesthetics with multi-hole catheters is an excellent analgesic alternative after cardiac surgery. ${ }^{[13]}$ Continuous BLS anesthetic perfusion decreases mobilization (dynamic) pain by $41 \%$, decreases pain at rest and morphine consumption (about 40\%). It allows earlier recovery, earlier food and oral treatment intake, earlier mobilization and greater patient satisfaction. ${ }^{[14]}$ 
The BLS perfusion decreases postoperative complications like postoperative delirium, respiratory infections and postoperative nausea and vomiting. ${ }^{[15]}$ An economic analysis demonstrated that BLS perfusion has a major economic benefit. A 90 -fold return on investment was calculated. The use of such perfusion after cardiac surgery involving sternotomy could have substantial economic benefits for healthcare facilities. ${ }^{[16]}$

The NSAIDs are also a good analgesic alternative after cardiac surgery. ${ }^{[1]}$ They modulate pain pathways through several mechanisms. They reduce inflammatory hyperalgesia and allodynia by reducing prostaglandin synthesis; they can decrease the recruitment of leucocytes, and consequently, their inflammatory mediators; finally, they cross the bloodbrain barrier to prevent the production of medullary neuromodulators. ${ }^{[18]}$ The NSAIDs decrease dynamic and the pain at rest, PONV and sedation, and opioid consumption. ${ }^{[19]}$

The safety of using NSAIDs to treat postoperative pain after cardiac surgery because of adverse effects is still a point of debate in the literature. Adverse effects of NSAIDs seem directly related to duration and exposure dose and should, therefore, be used at the lowest effective dose for the shortest possible time. ${ }^{[20]}$ However, are the NSAIDs really deleterious if they are used postoperatively in cardiac surgery with a low dose for 48 hours period? The gastric side effects related to NSAIDs are rare before five days, and renal toxicity is related to the patient's hemodynamic volume status. The NSAIDs did not increase the risk of renal impairment if they were prescribed in optimized doses, in the immediate postoperative period, in a normovolemic patient and in patients with low risk of renal dysfunction. ${ }^{[21]}$

The combination of BLS perfusion of local anesthetics, paracetamol and NSAIDs after cardiac surgery after sternotomy provides very satisfactory analgesia and allows a very significant decrease or even lack in opioid requirements. If a locoregional analgesic technique with local anesthetic could not be used, then, the combination paracetamol, NSAIDs and continuous intravenous lidocaine ${ }^{[22]}$ remains a good solution.

Peer-review

Internally peer-reviewed.

Conflict of Interest

None declared.

\section{REFERENCES}

1. Bigeleisen PE, Goehner N. Novel approaches in pain management in cardiac surgery. Curr Opin Anaesthesiol 2015;28:89-94. [CrossRef]

2. Mazzeffi M, Khelemsky Y. Poststernotomy Pain: A Clinical Review. J Cardiothorac Vasc Anesth 2011;25:1163-78. [CrossRef]

3. Jellish WS, Oftadeh M. Recovery After Surgery for Cardiac Surgery: Will We Have the Techniques Needed to Reduce Opioid Use and Still Provide Appropriate Analgesia? J Cardiothorac Vasc Anesth
2019;33:547-8. [CrossRef]

4. Chaney MA. How important is postoperative pain after cardiac surgery? J Cardiothorac Vasc Anesth 2005;19:705-7. [CrossRef]

5. Wheeler M, Oderda GM, Ashburn MA, Lipman AG. Adverse events associated with postoperative opioid analgesia: a systematic review. J Pain 2002;3:159-80. [CrossRef]

6. Nseir S, Hoel J, Grailles G, Soury-Lavergne A, Di Pompeo C, Mathieu D, et al. Remifentanil discontinuation and subsequent intensive care unit-acquired infection: a cohort study. Crit Care 2009;13:R60. [CrossRef]

7. Fletcher D, Martinez V. Opioid-induced hyperalgesia in patients after surgery: a systematic review and a meta-analysis. $\mathrm{Br} \mathrm{J}$ Anaesth 2014;112:991-1004. [CrossRef]

8. Oderda GM, Evans RS, Lloyd J, Lipman A, Chen C, Ashburn M, et al. Cost of opioid-related adverse drug events in surgical patients. J Pain Symptom Manage 2003;25:276-83. [CrossRef]

9. Lahtinen P, Kokki H, Hendolin H, Hakala T, Hynynen M. Propacetamol as adjunctive treatment for postoperative pain after cardiac surgery. Anesth Analg 2002;95:813-9. [CrossRef]

10. Cassuto J, Sinclair R, Bonderovic M. Anti-inflammatory properties of local anesthetics and their present and potential clinical implications. Acta Anaesthesiol Scand 2006;50:265-82. [CrossRef]

11. Landoni G, Isella F, Greco M, Zangrillo A, Royse CF. Benefits and risks of epidural analgesia in cardiac surgery. $\mathrm{Br} \mathrm{J}$ Anaesth 2015;115:25-32. [CrossRef]

12. Goldstein S, Dean D, Kim SJ, Cocozello K, Grofsik J, Silver P, et al, A survey of spinal and epidural techniques in adult cardiac surgery. $\mathrm{J}$ Cardiothorac Vasc Anesth 2001;15:158-68. [CrossRef]

13. Eljezi V, D'Ostrevy N. Local Anesthetic Diffusion of Bilateral Sternal Block After Cardiac Surgery. Reg Anesth Pain Med 2017;42:418-9.

14. Eljezi V, Dualé C, Azarnoush K, Skrzypczak Y, Sautou V, Pereira B, et al. The analgesic effects of a bilateral sternal infusion of ropivacaine after cardiac surgery. Reg Anesth Pain Med 2012;37:166-74. [CrossRef]

15. Eljezi V, Imhoff E, Bourdeaux D, Pereira B, Farhat M, Schoeffler P, et al. Bilateral sternal infusion of ropivacaine and length of stay in ICU after cardiac surgery with increased respiratory risk: A randomised controlled trial. Eur J Anaesthesiol 2017;34:56-65.

16. Mourgues C, Themista A, Eljezi V. Economic evaluation of bilateral sternal local anaesthetic infusions via multi-hole catheters after cardiac surgery. Eur J Anaesthesiol 2018;35:402-4. [CrossRef]

17. Eljezi V, Biboulet C, Boby H, Schoeffler P, Pereira B, Duale C. The Dose-Dependent Effects of Ketoprofen on Dynamic Pain after Open Heart Surgery. Pain Physician 2017;20:509-20.

18. Golan DE. Principles of Pharmacology: The Pathophysiologic Basis of Drug Therapy. Lippincott Williams \& Wilkins; 2008. p. 1012.

19. Elia N, Lysakowski C, Tramèr MR. Does multimodal analgesia with acetaminophen, nonsteroidal antiinflammatory drugs, or selective cyclooxygenase- 2 inhibitors and patient-controlled analgesia morphine offer advantages over morphine alone? Meta-analyses of randomized trials. Anesthesiology 2005;103:1296-304. [CrossRef]

20. Harirforoosh S, Asghar W, Jamali F. Adverse Effects of Nonsteroidal Antiinflammatory Drugs: An Update of Gastrointestinal, Cardiovascular and Renal Complications. J Pharm Pharm Sci 2013;16:821-47.

21. Acharya M, Dunning J. Does the use of non-steroidal anti-inflammatory drugs after cardiac surgery increase the risk of renal failure? Interact Cardiovasc Thorac Surg 2010;11:461-7. [CrossRef]

22. Weibel S, Jelting Y, Pace NL, Helf A, Eberhart LH, Hahnenkamp $\mathrm{K}$, et al. Continuous intravenous perioperative lidocaine infusion for postoperative pain and recovery in adults. Cochrane Database Syst Rev 2018; CD009642. [CrossRef] 